\title{
Isolation and Characterization of Yeast from Tomato Plants for Biological Control of Alternaria solani
}

\author{
G. Ashiwini* and B.C. Mallesha \\ Department of Agricultural Microbiology, College of Agriculture, University of Agricultural \\ Sciences, GKVK, Bengaluru-560065, Karnataka (India) \\ *Corresponding author
}

\section{A B S T R A C T}

\section{Keywords}

Yeasts, Tomato, Alternaria solani and Biocontrol activity

Article Info

Accepted:

15 June 2019

Available Online:

10 July 2019

\begin{abstract}
Nine different yeast isolates from various parts of tomato plant were isolated from two different locations of Bengaluru. The population on tomato leaves varied from 2.01-3.5 $\mathrm{x} 10^{4} \mathrm{cfu} / \mathrm{cm}^{2}$, on stems from 6.4-7.31 x10 $0^{4} \mathrm{cfu} / \mathrm{g}$ fresh weight and on fruits from 6.7-7.38 $\mathrm{x} 10^{4} \mathrm{cfu} / \mathrm{g}$ fresh weight. The yeast isolates were characterized for utilization of different carbon sources. Out of nine isolates, four yeast isolates TPL-I, RTPL, RTPS- II and RTPFII produced lipase enzyme. Further, they were evaluated for biocontrol activity against Alternaria solani in in vitro conditions. Among the yeast isolates, TPL-I yeast isolate showed strongly positive result by forming maximum zone of inhibition $(9 \mathrm{~mm})$, produced minimum dry mycelial weight $(40.07 \mathrm{mg})$ of pathogen and also showed highest percentage of inhibition of conidial germination $(80.50 \%)$ compared to other yeast isolates. Four yeast isolates produced relatively higher concentrations of IAA ranging from 0.21-0.68 $\mu \mathrm{g} / \mathrm{ml}$ and the maximum concentration of IAA was produced by TPL- I.
\end{abstract}

\section{Introduction}

Tomato (Solanum lycopersicum) is an important vegetable crop in India. Tomato has been a model plant to study and analyze various plant microbe interactions. (Conn and Tewari, 1990). Early blight of tomato, one of the dominant diseases in tomato caused by Alternaria solani causes average yield loss of $32-57 \%$. Symptoms of this disease include presence of irregular, often circular brown to dark brown colour leaf spots on the leaves with concentric lines inside the spots. Often the circular spots coalesce to form large patches resulting in the leaf blight. In several cases, small dark coloured spots are also formed on fruits and tender twigs (Pandey, 2003).

In a variety of crop protection scenarios, microbial biocontrol of plant diseases has emerged as an important strategy either to completely or partially reduce the use of chemical pesticides (Hassanien et al., 2003). It maintains the soil fertility and it is therefore an environment friendly approach. The surface of leaves usually referred to as the phylloplane or phyllosphere are normally colonized by a variety of bacteria, yeasts, and fungi. Exudations or secretions from plants 
contain simple sugars, organic acids and other compounds, which are the main nutrient source for such epiphytic microorganisms (Eglinton and Hamilton, 1967; Reisberg et al., 2013).

Ruinen (1963) reported that yeasts are a group of fungi in which unicellular form is predominant. As a group of microorganisms, yeasts have varied distribution. They have been isolated from natural substrates such as leaves, flowers, sweet fruits, grains, exudates of trees, insects, dung and soil. The external surface of leaves known as phyllosphere or phylloplane serves as an important habitat for many microbes including yeasts.

Yeasts are single-celled microorganisms which are evolutionally diverse and are therefore classified into two separate phyla, Ascomycota and Basidiomycota. They reproduce vegetatively by budding or fission, and produce sexual forms which are not enclosed in a fruiting body (Boekhout and Kurtzman, 1996). The yeast cells usually appear colourless, but when grown on artificial solid media they produce colonies which may be white, cream coloured or may contain pigments. Colony characteristics of yeasts become useful in knowing their taxonomy (Guarro et al., 1996).

Yurkov and Chernov (2005) isolated strains of three species of the ascomycetous yeasts from the above-ground parts of plants in Moscow and Novosibirsk regions. They were identified as Hanseniaspora guilliermondii, Torulaspora delbrueckii, and Debaryomyces hansenii. Many yeast colonies were also isolated from fruits like apple, green grapes, brown grapes, date fruits, jamun and fig, juices (date juice, toddy and cane juice) and milk showed antagonistic activity. Candida famata, Pichia membranifaciens and Rhodotorula mucilaginosa were antagonistic to Penicillium digitatum. The present investigation aims at obtaining the effective strains of yeasts that have potential biocontrol activity against Alternaria solani which causes early blight of Tomato.

\section{Materials and Methods}

\section{Isolation of yeasts}

The leaves, stems and fruits of tomato plants were collected from two different locations, one at the field experimental plots of Department of Plant Biotechnology, GKVK and another at a farmer's field in Rajankunte, Bengaluru for isolation of yeasts.

The leaves were punched and leaf discs (30 leaf discs) were made. The stems and fruits were also used for isolation of yeasts. All the samples were suspended in $100 \mathrm{ml}$ sterile distilled water blanks. After shaking for one hour, standard plate count technique was carried out for leaf, stem and fruit samples separately.

Diluted samples of $0.1 \mathrm{ml}$ were used for isolation of yeasts using Yeast Extract Malt Extract (YM) Agar Medium. The dilutions from $10^{-1}$ to $10^{-3}$ were used in the experiment. The plates were incubated at 27 ${ }^{\circ} \mathrm{C}$ for 48 hours. After incubation, population was recorded and nine dominant yeast isolates were isolated (3 isolates from leaves, 3 isolates from stems and 3 isolates from fruits).

\section{Characterization of yeast isolates}

\section{Microscopic observation of yeast isolates}

Yeast isolates were maintained on Potato Dextrose Agar (PDA) slants and used for further studies. The yeast isolates were studied for colony characteristics and cell shape. The observations of colony characters and cell shape were recorded by observing under microscope. 


\section{Carbon utilization test of yeast isolates}

Nine yeast isolates were tested for their growth on different carbon sources. YM agar medium was supplemented with $2 \%$ carbon sources and poured into petriplates. The nine yeast isolates were streaked on the medium and plates were incubated at $27 \pm 1^{\circ} \mathrm{C}$ for 24 hours. Growth was scored as no growth (-) and growth $(+)$.

\section{Lipolytic activity of yeast isolates}

The yeast isolates were examined for lipolytic activity by following the method of Oso (1978). The yeast isolates were streaked on the modified tributyrin agar plates and the clear zones around the colonies indicate the production of the lipase. Petriplates were incubated at $28{ }^{\circ} \mathrm{C}$ for 3 days and then observed for the clear zone around colonies.

\section{Biocontrol activity of yeast isolates against} Alternaria solani

\section{In vitro biocontrol activity of yeast isolates against Alternaria solani}

In vitro biocontrol activity of yeast isolates against Alternaria solani was evaluated by dual culture technique, $20 \mathrm{ml}$ of sterilized and cooled potato dextrose agar medium was poured into sterilized petriplates. The growth of Alternaria solani was evaluated by inoculating the pathogen at one side of the petriplate and the yeast isolates were inoculated by streaking exactly on the opposite side of the same plate by leaving 3-4 $\mathrm{cm}$ gap. For, this actively growing culture was used (Afsah-Hejri, 2013). A control petriplate inoculated with Alternaria solani alone was made. The plates were incubated at $28^{\circ} \mathrm{C}$ for 7 days and the mycelial growth of the fungi was observed. Growth of Alternaria solani was scored as highly positive result (++), slightly positive result (+) and negative result (-).

\section{Effect of yeast isolates on germination of conidia}

The effect of yeast isolates on the conidial germination of Alternaria solani was evaluated. Suspension of Alternaria solani was prepared from 7-day-old culture using Potato dextrose broth $(100 \mathrm{ml})$. Then, $5.0 \mathrm{ml}$ of the fungal suspension was mixed with 5.0 $\mathrm{ml}$ of 3 day old yeast suspensions in a test tube.

The test tubes were kept for incubation at 28 ${ }^{\circ} \mathrm{C}$ for 24 hours. These suspensions were mounted on the cavity slides. The germinating spores were observed and recorded under compound light microscope. The percentage inhibition of conidial germination of Alternaria solani was calculated by using the formula given by Channaveeresh and Shripad (2015):

Inhibition $(\%)$ of conidial germination $=$

Total number of conidia - number of germinated conidia

Total number of conidia $\mathrm{x} 100$

\section{Results and Discussion}

\section{Isolation of yeasts from tomato plants}

A total of nine yeast isolates (dominant on agar medium) were isolated from tomato plants procured from two different locations of Bengaluru.

Four yeast isolates, TPL- I and TPL- II from leaves, TPS from stem and TPF from fruits were isolated from the tomato plant samples collected at GKVK. Whereas, five yeast isolates RTPL from leaves, RTPS- I and RTPS- II from stem and RTPF- I and RTPFII from fruits were isolated from the tomato plant samples collected at Rajanakunte. 
Table.1 Morphological characteristics of yeast isolates

\begin{tabular}{|c|c|c|c|c|c|}
\hline Sl. No & Location & Plant part & $\begin{array}{c}\text { Yeast } \\
\text { Isolates }\end{array}$ & $\begin{array}{l}\text { Colony character } \\
\text { (on PDA medium) }\end{array}$ & $\begin{array}{c}\text { Shape and size } \\
(\mu \mathrm{m})\end{array}$ \\
\hline \multirow[t]{5}{*}{1.} & \multirow[t]{5}{*}{ GKVK } & Leaves & TPL-I & Pink, round & Oval $=1-2 \times 1-3$ \\
\hline & & Leaves & TPL-II & Dull white, round & Oval $=1-3 \times 1-3$ \\
\hline & & Stems & TPS & White, round & Oval=1-3 X 1-2 \\
\hline & & Fruits & TPF & Dull white & Oval=1-4X $1-4$ \\
\hline & & Leaves & RTPL & Bright white & Oval=1-4X $1-3$ \\
\hline \multirow[t]{4}{*}{2.} & \multirow[t]{4}{*}{ Rajanakunte } & Stems & RTPS-II & Cream & Oval $=1-3 \times \quad 1-4$ \\
\hline & & Fruits & RTPF-I & White & Oval=1-3X $1-2$ \\
\hline & & Fruits & RTPF-II & Yellow & Oval $=1-4 X \quad 1-3$ \\
\hline & & Stems & RTPS-I & White & Oval=1-3X 1-2 \\
\hline
\end{tabular}

Legend: TPL-Tomato Plant Leaf; TPS- Tomato Plant Stem; TPF- Tomato Plant Fruit; RTPL- Rajanakunte Tomato Plant Leaf; RTPS- Rajanakunte Tomato Plant Stem; RTPF- Rajanakunte Tomato Plant Fruit 
Int.J.Curr.Microbiol.App.Sci (2019) 8(7): 2043-2050

Table.2 Utilization of different carbon sources by yeast isolates of tomato

\begin{tabular}{|c|c|c|c|c|c|c|c|c|c|c|c|}
\hline $\begin{array}{c}\text { Yeast } \\
\text { Isolates }\end{array}$ & Glucose & Maltose & Sucrose & Lactose & Galactose & Starch & Mannitol & D-Ribose & L-Arabinase & D-Sorbitol & L-Rhamnose \\
\hline TPL-I & + & + & - & + & + & + & + & + & + & + & + \\
\hline TPL-II & + & + & + & + & + & + & + & + & + & + & + \\
\hline TPS & + & + & + & + & + & + & + & + & + & + & + \\
\hline TPF & + & + & + & + & + & + & + & + & + & + & + \\
\hline RTPL & + & - & + & - & - & - & - & - & - & - & - \\
\hline RTPS-I & + & + & + & + & + & + & + & + & + & + & + \\
\hline RTPS-II & + & + & + & + & + & + & + & + & + & + & + \\
\hline RTPF-I & + & + & + & + & + & + & + & + & + & + & + \\
\hline RTPF-II & + & - & - & + & + & - & + & + & + & + & + \\
\hline
\end{tabular}

Note:(+)Growth;(-)No-growth 
Figure.1 In vitro biocontrol activity of yeast isolates against Alternaria solani

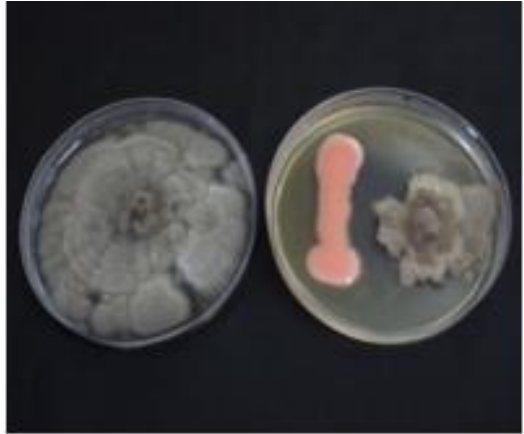

TPL-I

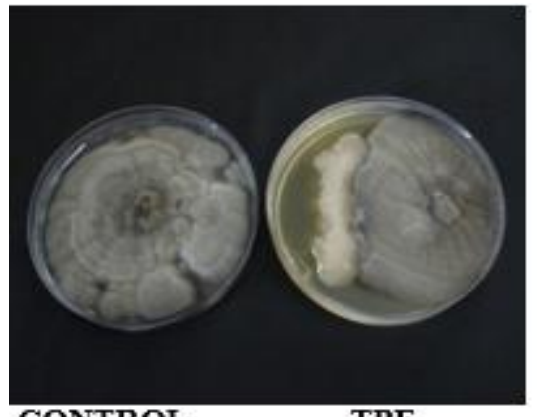

CONTROL

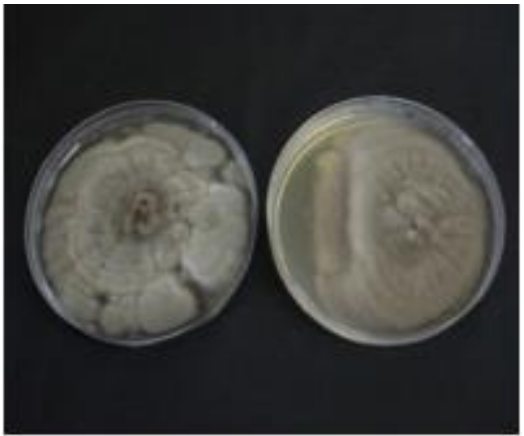

CONTROL RTPS-II

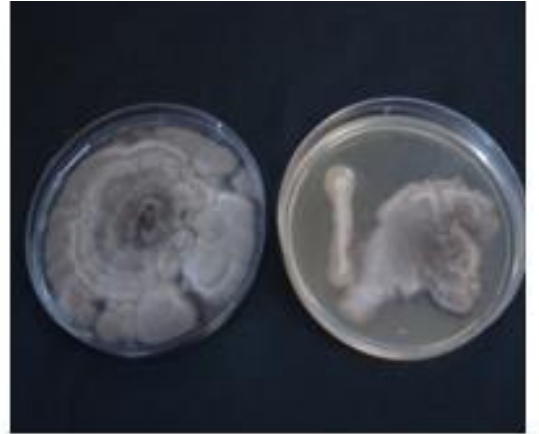

CONTROL TPL-II

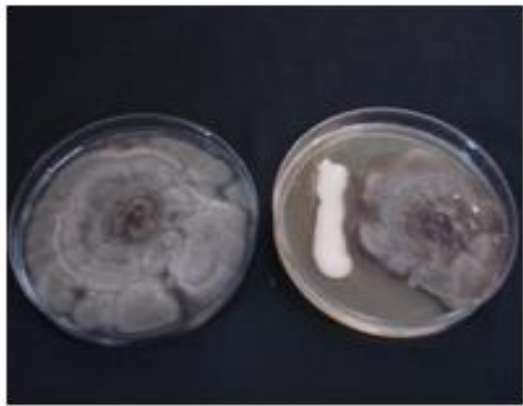

CONTROL



CONTROL

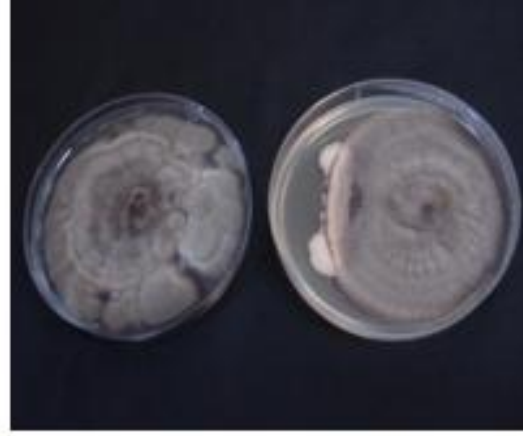

TPS

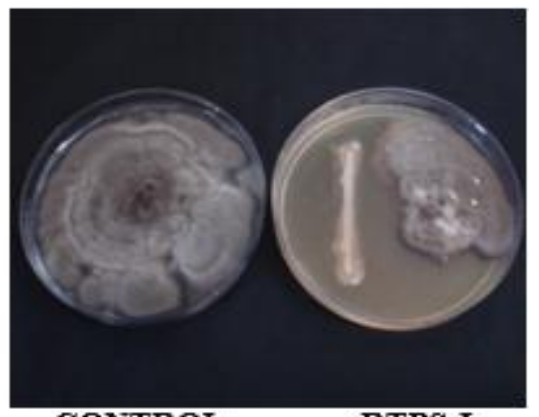

CONTROL

RTPS-I

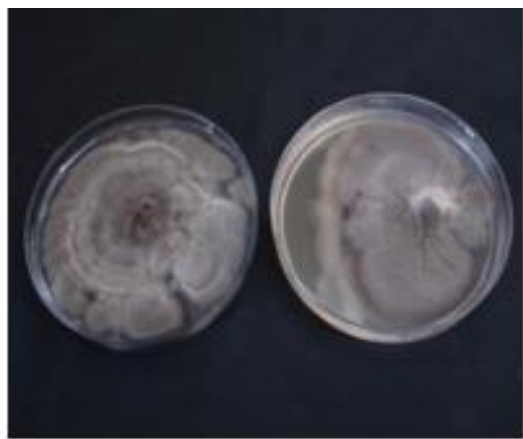

CONTROL

RTPF-II
Yeast population on the leaves, stem and fruits of tomato plants

The yeast population on leaves, stem and fruits of GKVK tomato plant samples were $3.5 \times 10^{4} \mathrm{cfu} / \mathrm{cm}^{2}, 6.4 \times 10^{4} \mathrm{cfu} / \mathrm{g}$ fresh weight and $6.7 \times 10^{4} \mathrm{cfu} / \mathrm{g}$ fresh weight respectively. Whereas, in Rajankunte tomato plant samples the yeast population on leaves were $2.01 \times 10^{4} \mathrm{cfu} / \mathrm{cm}^{2}$, on stems were $7.31 \mathrm{x}$ $10^{4} \mathrm{cfu} / \mathrm{g}$ and on fruits were $7.38 \times 10^{4} \mathrm{cfu} / \mathrm{g}$.
Cell morphology of yeast isolates under microscope

All the yeast isolates were observed under compound microscope. The yeast colonies were dull white to bright white, a few were pigmented. Cells were oval in shape and the size of the cell was measured in micrometer. Their size varied from 1 - 4 x 1 - $4 \mu \mathrm{m}$ (Table 1). 
Utilization of carbon source by the yeast isolates

The yeast isolates were tested for different carbon sources utilization. Different carbon sources (Eleven) were tested viz., glucose, maltose, sucrose, lactose, galactose, starch, mannitol, D- ribose, L- arabinose, D- sorbitol and $\mathrm{L}$ - rhamnose. The results on utilization of different carbon sources by yeast isolates of tomato plants are presented in Table 2 .

All the nine yeast isolates showed positive for utilization of glucose. TPL-I and RTPL-II were negative for sucrose while, RTPL and RTPF-II tested negative for maltose and starch. Except the yeast isolate RTPL, all the yeast isolates could use lactose, galactose, mannitol, D-Ribose L-Arabinase D-Sorbitol and L-Rhamnose.

\section{Lipolytic activity of yeast isolates of tomato}

All the nine yeast isolates were characterized for their lipolytic activity. Out of nine yeast isolates, four isolates TPL-I, RTPL, RTPS-II and RTPF-II were positive and remaining five isolates TPL-II, TPS, TPF, RTPS- I and RTPF-I were negative for lipolytic activity.

\section{Biocontrol activity of yeast isolates against Alternaria solani}

\section{In vitro biocontrol activity of yeast isolates against Alternaria solani}

Nine yeast isolates, isolated from leaves, stems and fruits of tomato plants were evaluated for their biocontrol activity against (Figure 1). Yeast isolate TPL- I showed highly positive result by inhibiting the growth of pathogen in the agar medium. It was followed by TPS, RTPL and RTPF-I which showed slight positive results. But there was no biocontrol activity observed in TPL- II, TPF, RTPS- I, RTPS- II and RTPF-II yeast isolates.
Effect of yeast isolates on inhibition of conidial germination $(\%)$

The effect of nine yeast isolates on inhibition of conidial germination of Alternaria solani was evaluated. All the nine yeast isolates were effective in inhibiting the conidial germination. Of these nine yeast isolates, TPL- I showed maximum inhibition of conidial germination $(80.50 \%)$ followed by TPS $(78.50 \%)$ and RTPL (43.19 \%). The lowest $(25.17 \%)$ conidial germination was observed in yeast isolate TPL- II after 24 hours of incubation.

In conclusions, the yeast population was more $\left(3.5 \times 10^{4} \mathrm{cfu} / \mathrm{cm}^{2}\right)$ on tomato leaves collected from GKVK compared to the yeast population on leaves collected from Rajanakunte. Also, fruits of tomato plants had more number of yeast isolates $\left(7.38 \times 10^{4}\right.$ $\mathrm{cfu} / \mathrm{g}$ fresh weight) compared to the stems of tomato plant $\left(7.31 \times 10^{4} \mathrm{cfu} / \mathrm{g}\right.$ fresh weight). Phaff (1986) reported that yeast population is high in the soil beneath the plants bearing fruits, they can sometimes migrate to leaves and fruits of those plants to obtain nutrients. Yeast cells use a wide variety of compounds as sources of energy for their growth and development. In this study, all the nine yeast isolates efficiently utilized glucose as the source of carbon over others. This observation was true in accordance with Cason and Reid (1987), they showed that glucose as an energy source will be taken up at faster rates than fructose by yeast cells. Also, among these nine yeast isolates, seven isolates utilized sucrose and starch as the carbon source but not all the yeast isolates. Bisson (1988) showed that yeast cells consume glucose or fructose in preference to other mono-, di- and trisaccharides, such as sucrose, raffinose or trehalose and prefer any fermentable carbon source over any other source, such as glycerol, ethanol, or acetate that has to be catabolized by oxidative phosphorylation. Also, among the nine yeast isolates 
characterized for their lipolytic activity, four yeast isolates TPL-I, RTPL, RTPS-II and RTPF-II produced lipases. In this study, tributyrin was used for the detection of lipases. Tweens and Tributyrin can also be hydrolyzed by esterases (Gupta et al., 2004). Many yeast species have shown their biocontrol activity against different plant pathogens. In dual culture method, among nine yeast isolates four yeast isolates showed positive results against Alternaria solani. TPL- I yeast isolate showed strongly positive results followed by yeast isolates TPS, RTPL and RTPF-I.

\section{References}

Afsah-Hejri, L., 2013, Saprophytic yeasts: effective biocontrol agents against Aspergillus flavus. Int. Food Res. J., 20(6): 3403-3409.

Bisson, L.F., 1988, High-affinity glucose transport in Saccharomyces cerevisiae is under general glucose repression control. J. Bacteriol., 170: 4838-4845.

Boekhout, T. and Kurtzman, C. P., 1996, Principles and methods used in the classification and an overview of currently accepted yeast genera. Nonconventional Yeasts in Biotechnol., 1: 1-99.

Cason, D. T., and Reid, G. C., 1987, On the differing rates of fructose and glucose utilization in Saccharomyces cerevisiae. J. Insl. Brew., 93 (1): 23-25.

Channaveeresh, T.S., and Shripad, K., 2015, In vitro evaluation of fungicides, bioagents and botanicals against Erysiphe polygoni DC in black gram.
IJPAS., 2(3): 41-53.

Eglinton, G., and Hamilton, R. J., 1967. Leaf epicuticular waxes. Science., 156: 1322-1335.

Guarro, J., Gene, J., and Stchigel, A.M. 1999, Developments in fungal taxonomy. Clin. Microbiol. Rev., 12: 454-500.

Gupta, R., Gupta, N., and Rathi, P., 2004, Bacterial lipases: An overview of production, purification and biochemical properties. Appl. Microbiol. Biotechnol., 64: 763-781.

Oso, B., 1978, The lipase activity of Talaromyces emersoni. Can. J. Bot., 56: 1840 - 1843.

Pandey, K. K., 2003, Resistance to early blight of tomato with respect to various parameters of disease epidemics. $J$. Gen. Plant Pathol., 69: 364-371.

Phaff, H.J., 1986, Ecology of yeasts with actual and potential value in biotechnology. Microbial Ecol., 12(1): 31-42.

Reisberg, E. E., Hildebrandt, U., Riederer, M., and Hentschel, U., 2013. Distinct phyllosphere bacterial communities on Arabidopsis wax mutant leaves. PLoS ONE., 8: e78613. doi: 10.1371/journal.pone.0078613.

Ruinen. J., 1963, The phyllosphere II. Yeasts from the phyllosphere of tropical foliage. Antonie Van Leeuwenhoek., 29: 425-438.

Yurkov, A. M., and Chernov. I. Y., 2005, Geographical races of certain species of ascomycetous yeasts in the Moscow and Novosibirsk regions. Microbiol., 74(5): $687-692$.

\section{How to cite this article:}

Ashiwini, G. and Mallesha, B.C. 2019. Isolation and Characterization of Yeast from Tomato Plants for Biological Control of Alternaria solani. Int.J.Curr.Microbiol.App.Sci. 8(07): 20432050. doi: https://doi.org/10.20546/ijcmas.2019.807.245 